\title{
Research on the Urban Edge Space Form of Tanhualin Historical Living Block in Wuhan
}

\author{
Sang Xiangrui ${ }^{1, *}$ \\ ${ }^{1}$ College of Civil Engineering and Architecture, Wuhan University of Technology, Wuhan, Hubei, 430070, China
}

\begin{abstract}
Edge space is not only the main place for residents' public activities, but also the key component of urban public space. It promotes people's spontaneous activities and social activities. Reasonable urban fringe space design can create the possibility for people to transform the city from bottom to top. While preserving the cultural background, Tanhualin historical life block has formed a rich and varied space form. This paper analyses the composition of its marginal space to explore the importance of edge space to urban public activities.
\end{abstract}

\section{Introduction}

From the point of view of psychology, architecture and environment constitute the relationship between the figure and the ground in the urban plane form. In the process of their identity switching, the boundary space plays a defining role. Although the proportion of marginal space in the city is small, it provides convenient and rich public places for people. In recent years, more and more scholars began to pay attention to the topic of "urban acupuncture design", trying to stimulate the internal vitality of the city through small-scale transformation, so as to achieve urban renewal from the bottom to the top. In my opinion, to control the shape of the edge space is an important link to revitalize the city.

Kevin Lynch divides cognitive elements into five types in The Image of the City, and edge is one of them. It is a linear space independent of the road element, which is generally but not necessarily the boundary of the two regions. [1] From the macro point of view, the edge can be reflected in the form of riverside and expressway of the urban boundary; from the micro perspective, the edge space is the transition space between buildings and buildings, buildings and roads, roads and districts, or between multiple districts, and plays a role of limiting the adjacent two areas. Based on the actual situation of Tanhualin historical life block, this paper mainly explores the form and composition of its small-scale edge space from the micro level.

\section{Research background}

\subsection{Overview of historical blocks}

Tanhualin historical living block is located in the northeast of Wuchang old city. It is surrounded by Zhongshan Road in the East, Desheng Bridge and Fenghuang Mountain in the west, Liangdao Street in the south and Zhongshan Road in the north, with a total length of about $1.2 \mathrm{~km}$. As a relatively well-preserved historical block, it has gathered dozens of outstanding buildings with a century-old history, including churches, schools, medical buildings and many former residences of celebrities (Fig. 1), which vividly reflect the development of cultural elements such as religion, education and urban life of the old Wuchang. [2] In the process of urban modernization, Tanhualin block has been transforming the block in response to the needs of modern residents while protecting the historical context, forming a unique spatial form with the coexistence of the old and the new, diverse culture and rich levels. It has developed into an important cultural place for leisure activities of local residents and sightseeing for foreign tourists.

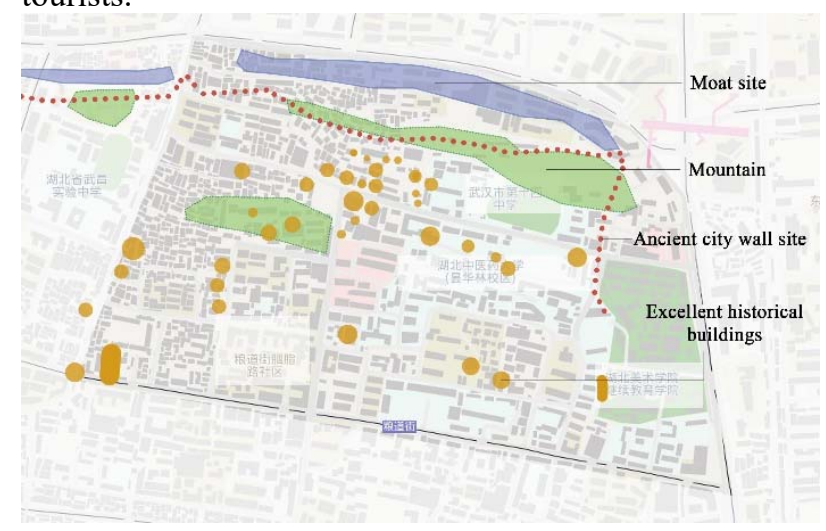

Fig. 1. Distribution map of historical and cultural elements in Tanhualin.

* Corresponding author: xiangruisang@whut.edu.cn 


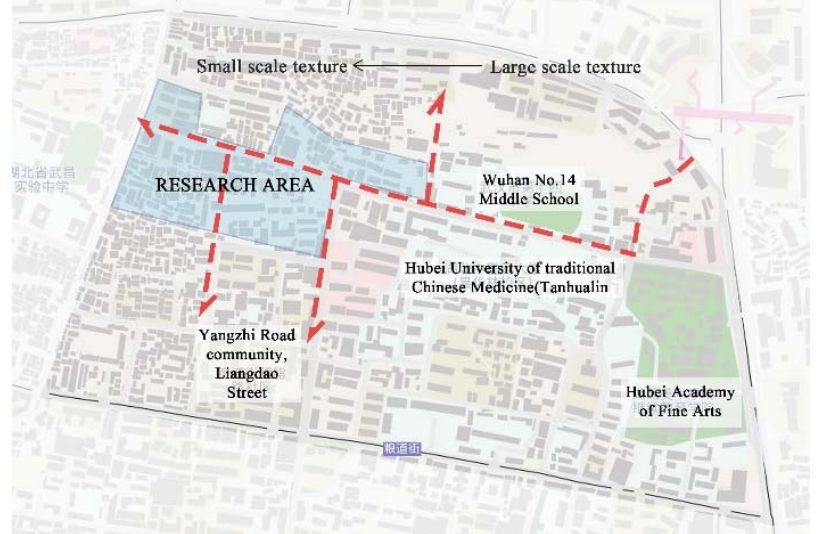

Fig. 2. Block texture and investigation route.

\subsection{Spatial structure and research route}

The whole Tanhualin block can be divided into three areas: commercial leisure, historical tour, and old city residence [3], but some of them interpenetrate with each other, forming a complex spatial form. The urban fabric transitions from the large-scale space to the small-scale living community from east to west, giving people a rich and varied space experience.

The survey time is selected in the time period from 2:00 pm to $5: 30 \mathrm{pm}$ on Wednesday to avoid the interference of the sudden increase of passenger flow on holidays to the normal state of life block. The survey route (Fig. 2) starts from Zhongshan Road in the East, and the entrance commercial area is dominated by large-scale space with pedestrian lines inside, echoing the texture of historical blocks, and realizing the transition from the main urban road to the Tanhualin historical block. In addition, subway stations and bus stops are located nearby, which is the main source of external passenger flow in the area. As a modern business district, small flower beds are often used to separate the building from the road in the edge of the building, or the corresponding pieces are placed according to the style of the store to attract tourists to stop, and various forms of seats are arranged to meet people's leisure needs (Fig. 3).

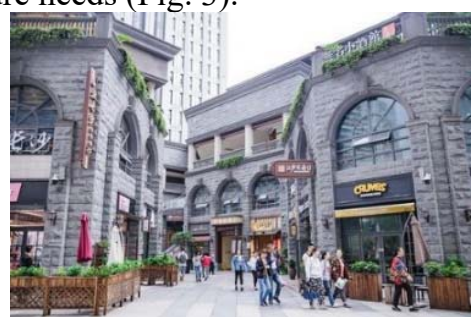

Fig. 3. Tanhualin business district.

The front section that officially enters the Tanhualin block will pass through Hubei University of Traditional Chinese Medicine and Wuhan No. 14 Middle School. Some modern buildings are preserved in this section, and now it has been transformed into functions of education, office or residence. The scale of the street is relatively large, and the vehicle and pedestrian areas are divided by paving transformation, planting of sidewalk trees and small road curbs, and mobile libraries and strip seats are installed at nodes to form a stay space (Fig. 4). The marginal space between the building and the road is raised according to the height difference. On the one hand, it can isolate the flow of people and traffic to protect the safety of pedestrians; on the other hand, it can be used as an extended outdoor space on the first floor of the building, with greenery in front of the door or leisure seats.

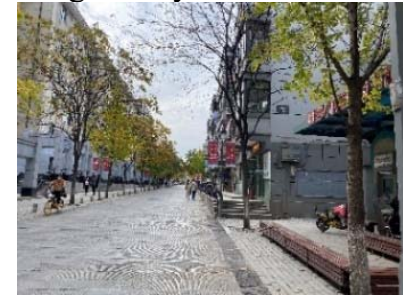

Fig. 4. Road and mobile library.

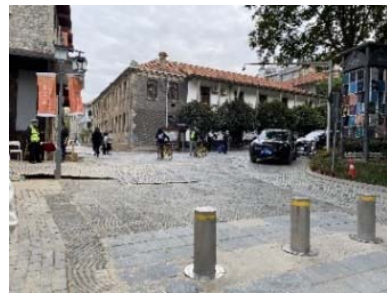

Fig. 5. Intersection of Tanhualin core area.
As we enter the core area of Tanhualin, the width of the road begins to shrink. At the same time, a liftable roadblock is set up at the entrance to block the passage of vehicles and define the scope of the pedestrian block (Fig. 5). Since then, it is the main research area of this paper. The core area of Tanhualin was originally dominated by a large number of small-scale residential areas and the remaining scattered religious, medical, educational and other types of historical preservation buildings. Later, with the main pedestrian street as the axis, the characteristic creative commerce was expanded to both sides. Combined with the terrain characteristics of the surrounding mountains, the horizontal street texture and scale change rich, and the vertical direction forms different views according to the terrain undulation. It is a special street with space experience. As the commercial pedestrian street on the central axis connects the residential areas on both sides of the north and south, which is one of the main routes for residents' daily life, so I also list it as a part of Tanhualin historical living block for investigation.

\section{Investigation of Tanhualin living block}

\subsection{Central road}

The pedestrian street in the center of Tanhualin is the main boundary dividing the north and south living communities, and the main place for people to go sightseeing and stroll. Its spatial form is embodied in a linear road connecting several node spaces of different scales (Fig. 6).

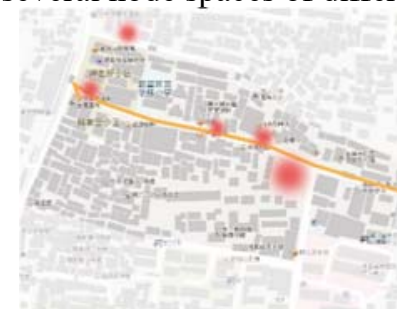

Fig. 6. Spatial form of central road.

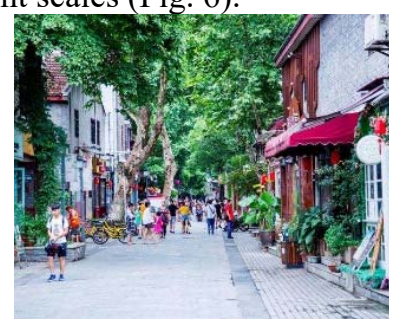

Fig. 7. The central road. 


\subsubsection{Linear road}

The construction of the marginal spaces on both sides of the linear road makes Tanhualin block form a harmonious style of petty bourgeoisie, culture and art, which is mainly reflected in three aspects: the street facade, plant decoration, and entrance step design (Fig. 7).

The change of pavement forms potentially divides the linear traffic in the center of the road and the edge space for people to stay at random on both sides of the road. Because most of the shops along the street are transformed from the first floor of the original residential buildings, and the building facades among different residential buildings are not forced to be unified. Therefore, diversity is created in the facade shape, material and color, which has the meaning of collage city. Some buildings have protruding balconies towards the street, which creates a sheltered gray space for the edge of the shop. Occasionally, residents sit on the doorstep to have a rest (Fig. 8). Some shops choose to use soft awning to delineate the entrance space for themselves as the transition to enter, or open windows beside the entrance to meet the needs of tourists (Fig. 9). They try to keep level with the facade of superstructure. Shops trying to keep level with the facade of the superstructure will give way to the entrance, forming an entrance platform that can put seats or decorative pieces, providing a place for people to stop when it rains.

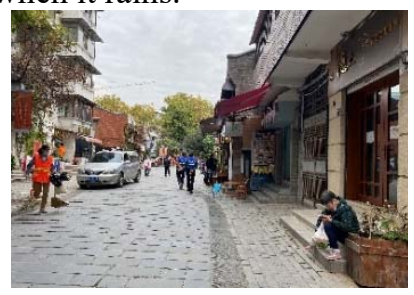

Fig. 8. Residents sit on the steps to rest.

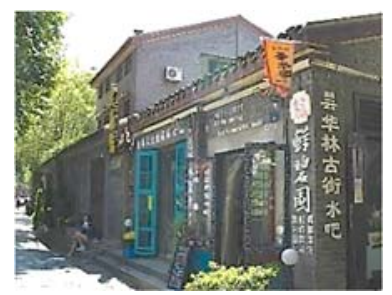

Fig. 9. Takeaway window.
In addition, the residents of Tanhualin district are very good at decorating the edge space with climbing plants such as Parthenocissus and small potted plants. The placement of some plants combined with the of entrance steps, with different heights, different leaf shapes and different colors, creates a small and delicate space atmosphere, attracting people to stay and watch at the edge of the road, and separates the noisy street from the quiet indoor environment of the shop. In addition to a few steps or a ramp at the entrance of some shops, sometimes there are narrow stairs along the edge of the building leading directly to the shops on the second floor. The side facade is usually decorated with color painting and other decorations. When there is a small flow of people, nearby residents sit here to rest (Fig. 10).

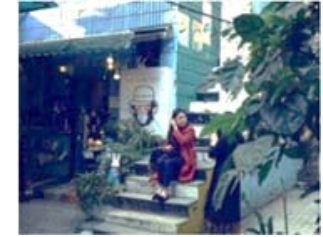

Fig. 10. People sitting on the steps to take pictures.

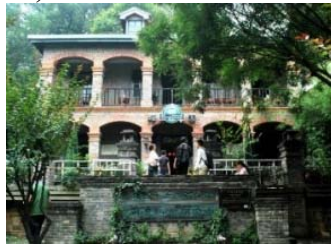

Fig. 11. The cafe behind Tanhualin Park.

\subsubsection{Node space}

Compared with the linear street, node space is a place for people to rest and communicate objectively. I regard it as the edge space of the whole street at a higher level. There is a large recreation square at the entrance of the core block, with high greening density and rest seats. The open private space is created through the shelter of trees. At the same time, it can lead to the building hidden behind the park (Fig. 11), which is the transition space between the road and the building. Walking along the pedestrian street, each section of the road will have a relatively open space for people to rest or used as a node for cultural promotion. According to the height difference, an elevated platform is formed and cultural sculptures are placed as symbolic meanings. This kind of edge space may be able to attract people's attention. However, if people sit down along the tree pools and flower beds for a rest, they may feel insecure about the view of the interior of the building behind. (Fig. 12) In contrast, it is more humanized to set wooden seats on the tree pool of arbors. The support on the back gives people a sense of psychological stability. People can rest and communicate at this node to alleviate the fatigue of walking. At the same time, they can have a positive sight communication with the surrounding shops and the crowd on the street. (Fig. 13)

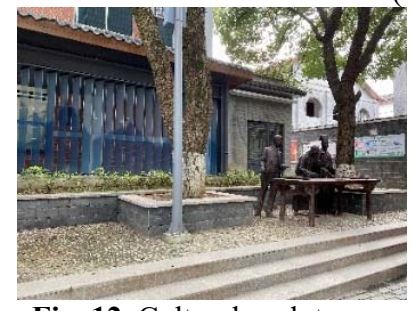

Fig. 12. Cultural sculptures on the roadside

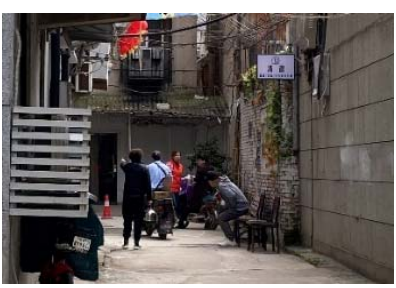

Fig. 14. People chat at the entrance of the community.

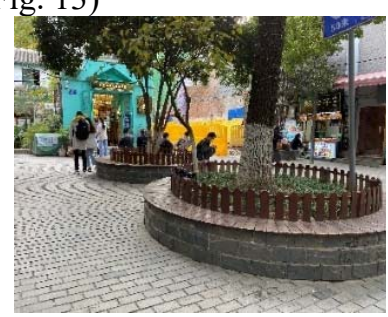

Fig. 13. Rest space at road node.

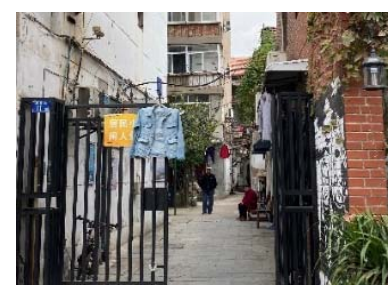

Fig. 15. Old people sit and rest at the entrance.

\subsection{Community space}

Compared with the central pedestrian street, the scale of community space is much narrower. For the closed community, residents seem to like to sit at the entrance of the lane for chatting (Fig. 14), perhaps because they can often meet acquaintances and can observe the movement of the outside crowd. As the old residential area did not consider providing special outdoor activity places for residents, the residents constantly spontaneously moved seats from their homes (Fig. 15), and reformed the 
relatively open edge space from bottom to top, which greatly improved the utilization rate of space.

For the open community formed by the intersection of large and small roadways in the south, the scale changes are more diverse and even slightly disordered. The influence factors of buildings on the edge space lie in two aspects: one is whether there is a balcony overhanging from the upper floor (Fig. 16), which gives people a sense of security due to being sheltered, which makes the external space penetrate inward, resulting in the trend of guiding people to enter the interior [4]; the second is whether there is a height difference between the building and the external road. At this time, steps and its attached platform become another element of the edge space.

If the building is higher than the road, the raised platform becomes the outward extension of the internal space. The elderly are glad to rest in front of their own house and sometimes talk to friends passing by. In summer, it may become a good place to eat, play chess and enjoy the cool (Fig. 17). If the building is basically level with the road, the edge space will often be transited by one or two steps or a gentle slope, and people's gathering behavior depends on whether it is open enough; if the building plane is lower than the road, considering the problem of rainwater backflow, this situation should be rare, and there is usually a circle of transitional space around the building to strengthen the sense of boundary of the building.

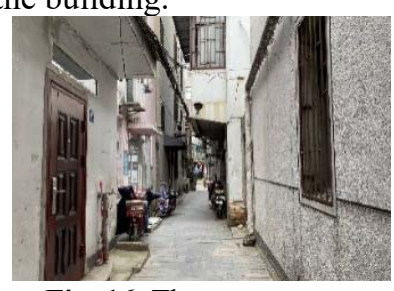

Fig. 16. The grey space formed by the balcony.

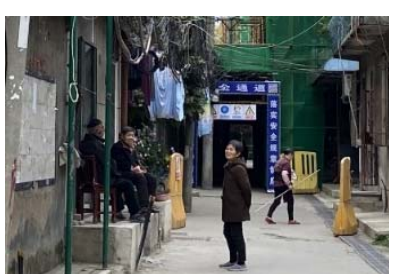

Fig. 17. The old sat on the platform and chatted.

In addition, the utilization rate of plants in the marginal space of the community is also very high. It fills the gap formed by the road in the plane view (Fig. 18), or decorates and guides the building entrance to enrich the street landscape and enhance the space vitality. During the investigation, we also saw interesting scenes. A resident standing outside communicated with the people inside directly through the window sill directly (Fig. 19). This kind of scene may be difficult to meet in the modern community, which fully reflects the humanity and community flavor of Tanhualin historical living block, and enriches the activity form of the crowd in the building edge space.

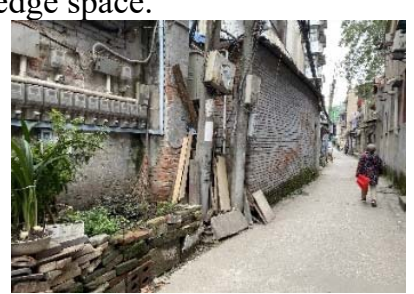

Fig. 18. Plant beside community Lane.

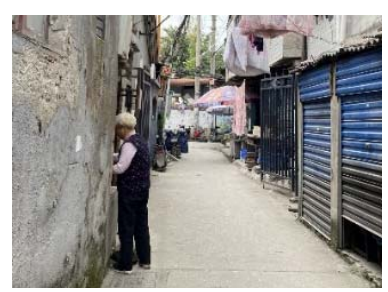

Fig. 19. The old woman communicated with the residents inside the house.

\section{The relationship between marginal space and behavior}

\subsection{User perspective}

According to the research of environmental psychology, compared with being in the center of outdoor space, the edge of building exterior wall, space boundary and other places can provide people with a sense of psychological protection, that is, the marginal tendency of behavior [5], which reflects in the living community is the marginal space mentioned in the article. Some scholars divide people's behavior activities in urban public space into three types, namely necessary activities, spontaneous activities and social activities. [6] In addition to the necessary activities may occur in specific places, which cannot be greatly affected by the environment, other forms of activities are subject to random changes due to the conditions of urban environment. From the survey, we can find that the edge space can provide a place for various forms of activities such as rest and conversation without disturbing other regional activities, which fully stimulates people's instinct to use public space and participate in public activities. Residents are willing to carry out spontaneous transformation of small space, so as to make the environment more adapt to the needs of their life. Edge space provides a foothold for people's fast-paced urban life, gathering emotions separated by reinforced concrete in every corner, trying to wake up the vitality of the city from the bottom up.

\subsection{Urban design perspective}

If the edge is defined as a clear boundary, the edge space is a more subjective area that spreads out to the surrounding area according to this line, and the scope is often between the architectural ancillary space and the urban functional space. Its use nature is not clearly defined to provide conditions for users to create diversified activities. From the negative aspect, the edge space does not play a major role in the composition of the city. In many cases, due to its vague intermediary, it is easily ignored by designers, resulting in the reduction of the utilization rate of public space; from the positive perspective, urban design can guide people's behavior and activities through the construction of edge space, and promote people to return to public life from closed rooms. The design has always been people-oriented. In the process of investigation, we have observed many spontaneous activities in the edge space. However, some small-scale roadways in the current living community may not be comfortable enough for residents. Narrow space and old facilities will bring bad space experience. Therefore, for the edge space of urban blocks, designers need to carry out comprehensive transformation from the aspects of scale, atmosphere and use experience, so that the urban environment and residents can better interact.

\section{Conclusion}

The development of modern cities provides convenience 
for people's life, but the state of being accessible without leaving home makes people lose enthusiasm for public life. The development and reconstruction of Tanhualin historical life block symbolizes the vitality which is independent of the tide of urbanization. It maintains the vitality of the city from the inside to the outside with the distinct spirit of place and the close communication between people. The rich edge space provides an opportunity for people's emotional collision. As a smallscale urban design, it plays an important role in retaining urban characteristics and expanding public space.

\section{References}

1. K. Lynch. Trans. Xiang Bingren. The Image of the City $[\mathrm{M}]$. China Construction Industry Press, Beijing. (1990)

2. Luo Caixia. Planning and design of public space in Tanhualin historical and Cultural District [D]. Huazhong Agricultural University. (2012)

3. Wang Wenhui, Yuan Liping. Discussion on the renewal and activation strategy of historical blocks under the concept of "urban repair" -- Taking Tanhualin historical block in Wuhan as an example [C]. Proceedings of 2019 China Urban Planning Annual Conference (02 urban renewal). China Urban Planning Society, Chongqing Municipal People's Government: China Urban Planning Society. (2019:2039-2049.)

4. Chen Wenjia, Zhu Chunyang, Zhou Yi. Study on the edge space form of urban life block -- Taking Tanhualin historical life block as an example [J]. Central China architecture. (2014,32 (04): 63-70)

5. Yao Xiaoyan. Study on the design of modern urban street edge space [D]. Hebei Agricultural University. (2007)

6. Jan Gail. Trans. He Renke. Life between buildings [M]. Beijing: China Construction Industry Press. (2002:13-17) 